\title{
THE POSSIBILITIES OF RECOVERY OF SELECTED METALS FROM LITHIUM BATTERIES BY PYROMETALLURGICAL WAY
}

\author{
${ }^{1}$ Jitka MALCHARCZIKOVÁ, ${ }^{2}$ Lukáš KROČA, ${ }^{1}$ Miroslav KURSA, ${ }^{1}$ Pavel HORÁK \\ ${ }^{1}$ VSB - Technical University of Ostrava, Ostrava, Czech Republic, EU \\ jitka.malcharczikova@vsb.cz,miroslav.kursa@vsb.cz \\ ${ }^{2}$ Kovohutě Príbram nástupnická, a.s., Príibram, Czech Republic, EU \\ kroca@kovopb.cz
}

https://doi.org/10.37904/metal.2019.948

\begin{abstract}
Some recycling technologies are used to processing of waste lithium batteries. The treatment can be carried out pyro-metallurgically, hydro-metallurgically or both with respect to which metals must be obtained. Still looking for new ways to effectively process the waste Li batteries, so for example bio-metallurgy is also used. The Li-lon batteries also contain other metals such as cobalt, copper, nickel and aluminium outside of lithium, which are very difficult to obtain. There are many types of lithium batteries, and the content of these metals is variable in each battery components. This paper is focused on the recovery of these metals by a pyrometallurgical process using a collector.
\end{abstract}

KEYWORDS: Lithium batteries, cobalt, pyrometallurgy, recycling, metals recovery

\section{INTRODUCTION}

Recycling of batteries and accumulators containing lithium is at the forefront of scientific interest. The recycling processes were initially focused on recovering only selected metals - cobalt, nickel, and manganese using pyro- and hydro-metallurgical techniques. The process of the mechanical separation of copper and aluminium or Fe was added later. Nowadays, numerous processing technologies for this type of batteries have been developed, including those aimed at obtaining lithium. Given the pressure to increase the share of battery recycling (increasing the proportion of materials used as secondary raw materials) and the increasing cost and demand for lithium, technologies are being introduced that enable obtaining both lithium and other metals as well as plastic materials. With the increasing production of electric vehicles and hybrid vehicles, the development of photovoltaic elements and EEE, the volume of lithium batteries will increase significantly. Lithium batteries contain hazardous components, and under certain conditions, they may be hazardous, which makes their recycling difficult [1-7].

Production of lithium batteries and accumulators continues to grow in the world, and more new types of batteries are being developed. Therefore, it is very difficult to determine the exact content of metals and other non-metallic components contained in them. Cobalt I highly valuable raw material, the gain of which is currently the most important economic parameter for recycling. As stated in [8], the lithium content in Li-lon batteries (LiB) is in the range of 2-5\%, cobalt content in LiBs is up to $20 \%$. After separation of the electrode mass itself, the content of the metals of interest is higher in this fraction.

Given the processing technology used, the selected process conditions and the equipment used, it is possible to obtain various components that can be used as secondary raw materials. New and better technologies are still being developed in a number of already running research projects. In the case of new processes, an emphasis is also put on the possibility of repeated use of the recovered secondary raw materials for battery production. 


\section{DESCRIPTION OF THE EXPERIMENT}

For the experiment, an electrode mass of Li-lon batteries without a magnetic fraction was used. The batteries from laptops were crushed in a hammer crusher to remove magnetic particles. Subsequently, this material was screened, and a portion of undersize smaller than $0.4 \mathrm{~mm}$ was further used.

To obtain selected metals, a pyro-metallurgical process was used, in which copper was used as a collector. Copper was obtained after the processing of copper cables.

\subsection{Preparation of the experiment}

The electrode mass was annealed at $500^{\circ} \mathrm{C}$ to constant weight. After annealing, a weight loss of about $13 \%$ was found after a dwell of 40 minutes at a given temperature. The content of selected elements into LIB mass was determined by ED-XRF (Energy Dispersive X-ray Fluorescence) spectrometry, as in the initial state and after annealing. Charges contained 5, 10 and $15 \mathrm{wt} \%$ of LIB mass. The samples were made by induction melting and centrifugally cast into a graphite mould. The metal content in the castings was observed by OES (optical emission spectrometry) and ED-XRF spectrometry. After annealing, the metal content in the mass increased, and the cobalt content was then approx. $45 \mathrm{wt} \%$. The determined contents of the selected elements are shown in Table 1.

Table $1 \mathrm{ED}-\mathrm{XRF}$ analysis of LIB material - annealing, $500{ }^{\circ} \mathrm{C}$

\begin{tabular}{|c|c|c|c|c|c|c|c|c|c|c|c|c|}
\hline \multirow{2}{*}{ Sample } & \multirow{2}{*}{$\begin{array}{l}\text { An. } \\
\text { No. }\end{array}$} & Co & $\mathrm{Cu}$ & $\mathrm{Ni}$ & $\mathrm{Al}$ & $\mathrm{Si}$ & $\mathrm{Mn}$ & $\mathrm{Fe}$ & $\mathrm{Zn}$ & $\mathrm{Pb}$ & Sn & $\mathrm{Cd}$ \\
\hline & & \multicolumn{11}{|c|}{ Content of metals (wt\%) } \\
\hline \multirow{4}{*}{ LIB 1} & 1 & 45.48 & 2.61 & 3.10 & 1.10 & 1.41 & 3.43 & 0.3608 & 0.6567 & 1.84 & 0.0297 & 0.0717 \\
\hline & 2 & 45.47 & 4.15 & 2.86 & 1.83 & 1.40 & 3.01 & 0.3418 & 0.6301 & 1.96 & 0.0112 & 0.0505 \\
\hline & 3 & 46.10 & 2.95 & 3.09 & 1.33 & 1.35 & 3.55 & 0.4184 & 0.8430 & 1.53 & 0.0154 & 0.0586 \\
\hline & 4 & 43.82 & 6.31 & 2.86 & 1.60 & 1.46 & 3.33 & 0.3629 & 0.7382 & 1.48 & 0.0063 & 0.0992 \\
\hline \multirow{3}{*}{ LIB 2} & 5 & 46.67 & 2.01 & 2.95 & 1.04 & 1.43 & 2.94 & 0.4117 & 0.7176 & 1.53 & 0.0090 & 0.0648 \\
\hline & 6 & 42.97 & 6.74 & 2.64 & 1.44 & 1.51 & 2.94 & 0.3628 & 0.8968 & 1.86 & 0.0089 & 0.0468 \\
\hline & 7 & 46.31 & 2.38 & 2.96 & 1.04 & 1.38 & 3.21 & 0.4050 & 0.6465 & 1.56 & 0.0130 & 0.0586 \\
\hline \multirow{5}{*}{ LIB 3} & 8 & 48.55 & 2.49 & 2.77 & 1.31 & 1.42 & 3.04 & 0.3398 & 0.7162 & 2.02 & 0.0154 & 0.0467 \\
\hline & 9 & 44.32 & 3.66 & 2.69 & 1.48 & 1.37 & 2.82 & 0.4783 & 0.7304 & 1.61 & 0.0249 & 0.0569 \\
\hline & 10 & 45.19 & 2.47 & 2.84 & 1.15 & 1.45 & 3.08 & 0.3504 & 0.6543 & 1.53 & 0.0452 & 0.0535 \\
\hline & Avera-ge & 45.49 & 3.58 & 2.88 & 1.33 & 1.42 & 3.14 & 0.3832 & 0.7230 & 1.69 & 0.0179 & 0.0607 \\
\hline & Devia-tion & 1.50 & 1.59 & 0.15 & 0.25 & 0.04 & 0.22 & 0.0419 & 0.0828 & 0.19 & 0.0114 & 0.0148 \\
\hline
\end{tabular}

Copper with a purity of min. 3N6, which was separated after the processing of copper cable waste, was used as a collector. Charge - $\mathrm{Cu}$ and annealed LIB mass - is shown in Figure 1. Pure copper and annealed LIB mass were used for the charge. Charges of copper and LIB masses containing 5, 10 and 15 wt $\%$ were prepared for the heats. Castings made of copper and LIB mass are hereinafter referred to as LIB5, LIB10 and LIB15. The castings made of pure copper are referred to as $\mathrm{Cu} 1$ and 2 - wire. The melting point was chosen for pure $\mathrm{Cu}$ at $1200^{\circ} \mathrm{C}$ and for mixture of copper and mass at $1550{ }^{\circ} \mathrm{C}$. The charges were approximately $80 \mathrm{~g}$ with respect to the size of the crucible. 

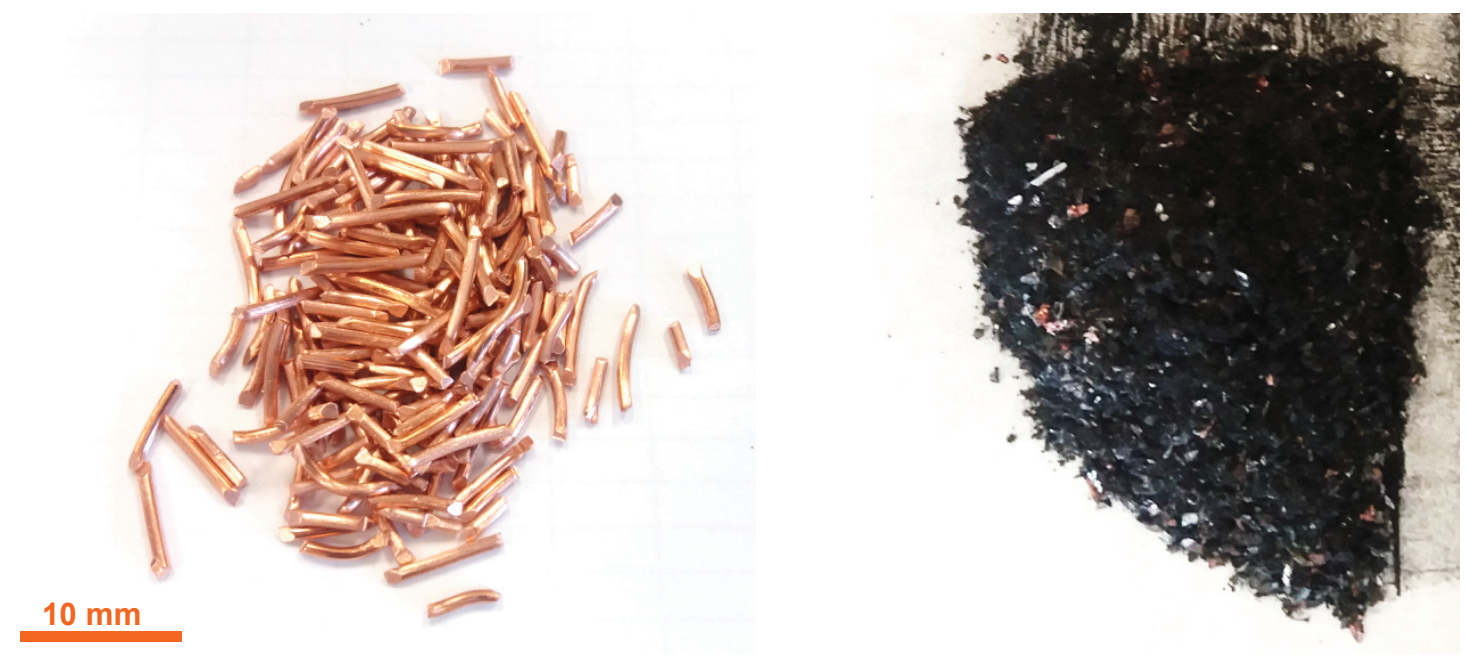

Figure 1 Charge - Cu and annealed LIB mass

\subsection{Pyro-metallurgical process of metals recovery}

The heats were performed in the equipment SUPERCAST 13 by the method of induction melting in an argon atmosphere, and then they were centrifugally cast into graphite mould (Figure 2). In this way, the cylinders with a diameter of $25 \mathrm{~mm}$ (Figure 3) were obtained. The castings were machined, cut at given points, and the chemical composition was determined by optical emission spectrometry (OES) using a SPECTROMAXx spectrometer. Control measurements were performed by the ED-XRF method using a Delta Professional spectrometer, acquired within the frame of the RMSTC project. The chemical composition of selected metals determined by both methods is comparable. The values of metal content determined by the OES method are shown in Table 2.
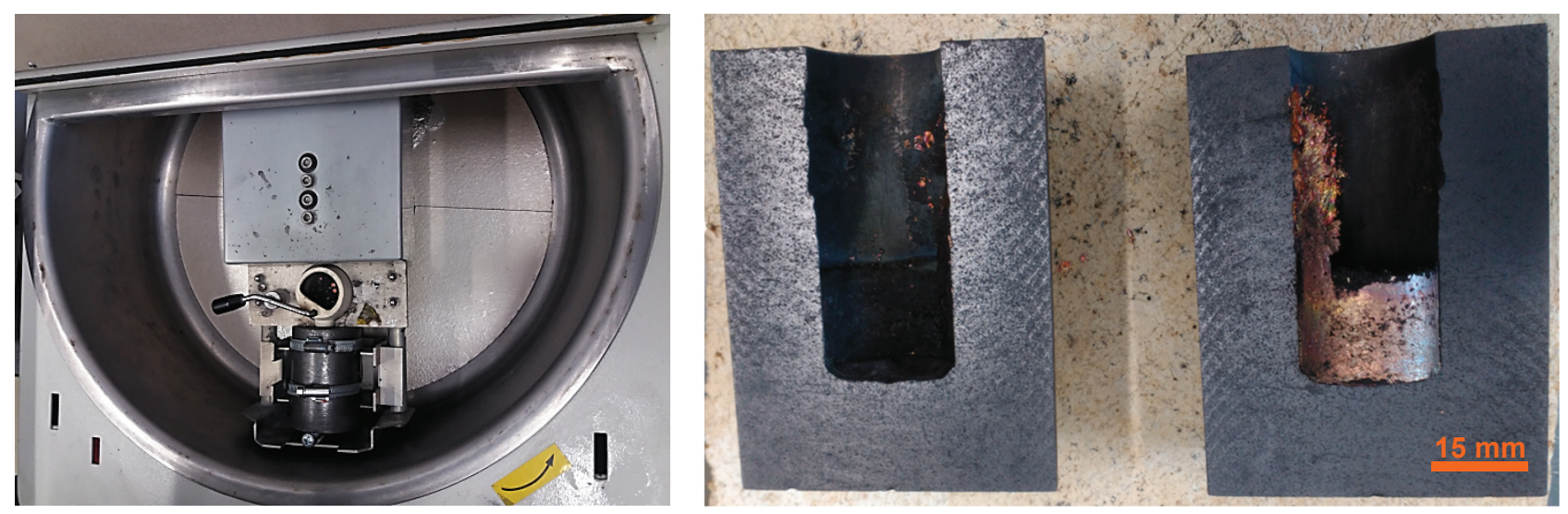

Figure 2 Melting and casting equipment, casting in a graphite mould

Figure 2 shows on the left the inside space of the furnace with the prepared charge in a corundum crucible and a graphite mould. The figure shows on the right the final casting in the mould. Figure 3 shows on the left one of the castings cleaned from the rest of the LIB mass, and on the right 2 samples already prepared for chemical analysis using the OES method (Figure 4) and ED-XRF.

The measurement was performed at 3 points of the casting - in the upper, middle and bottom parts of the casting. The points of measurement are shown in Table 2 as upper, middle and bottom. It can be seen from Table 2 that the contents of the selected metals are similar at all three points of measurement and the castings are therefore homogeneous. 

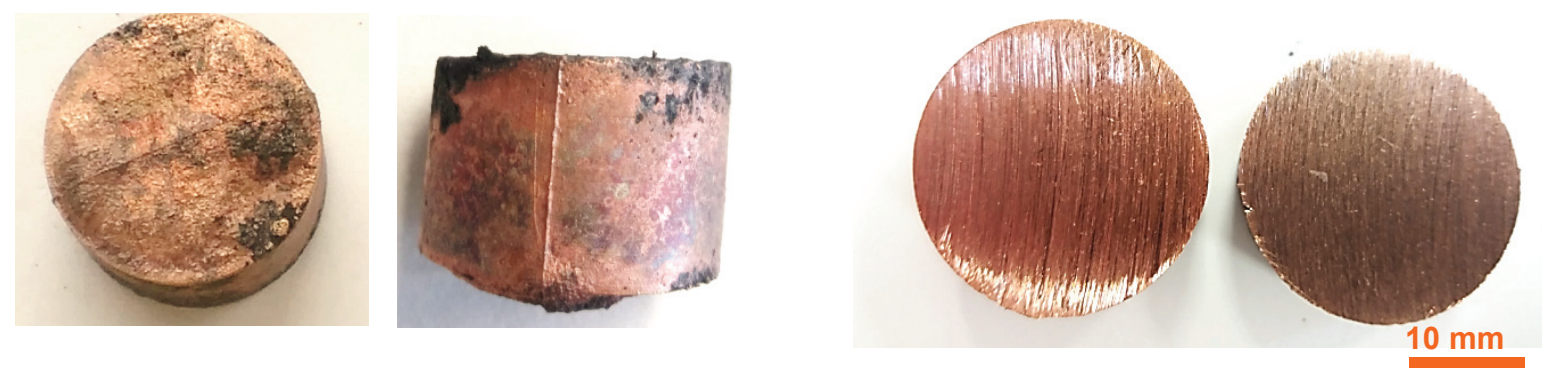

Figure 3 Cu casting with Co and other metals from LIB material

Table 2 OES analysis of pure copper and Cu collector (wt\%)

\begin{tabular}{|c|c|c|c|c|c|c|c|c|c|c|c|}
\hline Sample & $\begin{array}{c}\text { Point of } \\
\text { meas. }\end{array}$ & Co & $\mathrm{Cu}$ & $\mathrm{Ni}$ & $\mathrm{Al}$ & Si & Mn & $\mathrm{Fe}$ & $\mathrm{Zn}$ & $\mathrm{Pb}$ & C \\
\hline \multirow{4}{*}{$\begin{array}{l}\text { Cu } 1 \\
\text { wire }\end{array}$} & Upper & 0.0000 & 99.9657 & 0.0057 & 0.0000 & 0.0000 & 0.0000 & 0.0000 & 0.0055 & 0.0000 & 0.0014 \\
\hline & Bottom & 0.0000 & 99.9711 & 0.0050 & 0.0000 & 0.0000 & 0.0000 & 0.0000 & 0.0051 & 0.0000 & 0.0023 \\
\hline & Average & 0.0000 & 99.9684 & 0.0054 & 0.0000 & 0.0000 & 0.0000 & 0.0000 & 0.0053 & 0.0000 & 0.0019 \\
\hline & Deviation & 0.0000 & 0.0027 & 0.0004 & 0.0000 & 0.0000 & 0.0000 & 0.0000 & 0.0002 & 0.0000 & 0.0005 \\
\hline \multirow{4}{*}{$\begin{array}{l}\text { Cu } 2 \\
\text { wire }\end{array}$} & Upper & 0.0000 & 99.9607 & 0.0035 & 0.0000 & 0.0062 & 0.0000 & 0.0000 & 0.0052 & 0.0000 & 0.0061 \\
\hline & Bottom & 0.0000 & 99.9648 & 0.0034 & 0.0000 & 0.0032 & 0.0000 & 0.0000 & 0.0058 & 0.0000 & 0.0044 \\
\hline & Average & 0.0000 & 99.9628 & 0.0035 & 0.0000 & 0.0047 & 0.0000 & 0.0000 & 0.0055 & 0.0000 & 0.0053 \\
\hline & Deviation & 0.0000 & 0.0020 & 0.0001 & 0.0000 & 0.0015 & 0.0000 & 0.0000 & 0.0003 & 0.0000 & 0.0009 \\
\hline \multirow{5}{*}{$\begin{array}{l}\text { Cu } 3 \\
\text { LIB5 }\end{array}$} & Upper & 0.1840 & 99.5013 & 0.0280 & 0.0000 & 0.0054 & 0.0088 & 0.0000 & 0.0000 & 0.2430 & 0.0037 \\
\hline & Middle & 0.1860 & 99.4717 & 0.0270 & 0.0010 & 0.0170 & 0.0084 & 0.0000 & 0.0000 & 0.2390 & 0.0200 \\
\hline & Bottom & 0.1810 & 99.5292 & 0.0270 & 0.0062 & 0.0000 & 0.0110 & 0.0000 & 0.0000 & 0.2120 & 0.0032 \\
\hline & Average & 0.1837 & 99.5007 & 0.0273 & 0.0024 & 0.0075 & 0.0094 & 0.0000 & 0.0000 & 0.2313 & 0.0090 \\
\hline & Deviation & 0.0021 & 0.0235 & 0.0005 & 0.0027 & 0.0071 & 0.0011 & 0.0000 & 0.0000 & 0.0138 & 0.0078 \\
\hline \multirow{5}{*}{$\begin{array}{c}\text { Cu } 4 \\
\text { LIB10 }\end{array}$} & Upper & 0.6900 & 98.6752 & 0.0940 & 0.0092 & 0.0000 & 0.0630 & 0.0056 & 0.0130 & 0.4080 & 0.0050 \\
\hline & Middle & 0.7000 & 98.6479 & 0.0950 & 0.0086 & 0.0110 & 0.0640 & 0.0062 & 0.0130 & 0.4030 & 0.0160 \\
\hline & Bottom & 0.7000 & 98.6615 & 0.1020 & 0.0130 & 0.0000 & 0.0650 & 0.0069 & 0.0140 & 0.3990 & 0.0078 \\
\hline & Average & 0.6967 & 98.6615 & 0.0970 & 0.0103 & 0.0037 & 0.0640 & 0.0062 & 0.0133 & 0.4033 & 0.0096 \\
\hline & Deviation & 0.0047 & 0.0111 & 0.0036 & 0.0019 & 0.0052 & 0.0008 & 0.0005 & 0.0005 & 0.0037 & 0.0047 \\
\hline \multirow{5}{*}{$\begin{array}{c}\text { Cu } 5 \\
\text { LIB15 }\end{array}$} & Upper & 1.1100 & 97.5955 & 0.1740 & 0.0120 & 0.0220 & 0.1470 & 0.0150 & 0.0270 & 0.8000 & 0.0350 \\
\hline & Middle & 1.1800 & 97.5296 & 0.1880 & 0.0120 & 0.0330 & 0.1420 & 0.0140 & 0.0270 & 0.7900 & 0.0340 \\
\hline & Bottom & 1.0800 & 97.6534 & 0.1690 & 0.0110 & 0.0300 & 0.1350 & 0.0140 & 0.0290 & 0.7900 & 0.0290 \\
\hline & Average & 1.1233 & 97.5928 & 0.1770 & 0.0117 & 0.0283 & 0.1413 & 0.0143 & 0.0277 & 0.7933 & 0.0327 \\
\hline & Deviation & 0.0419 & 0.0506 & 0.0080 & 0.0005 & 0.0046 & 0.0049 & 0.0005 & 0.0009 & 0.0047 & 0.0026 \\
\hline
\end{tabular}




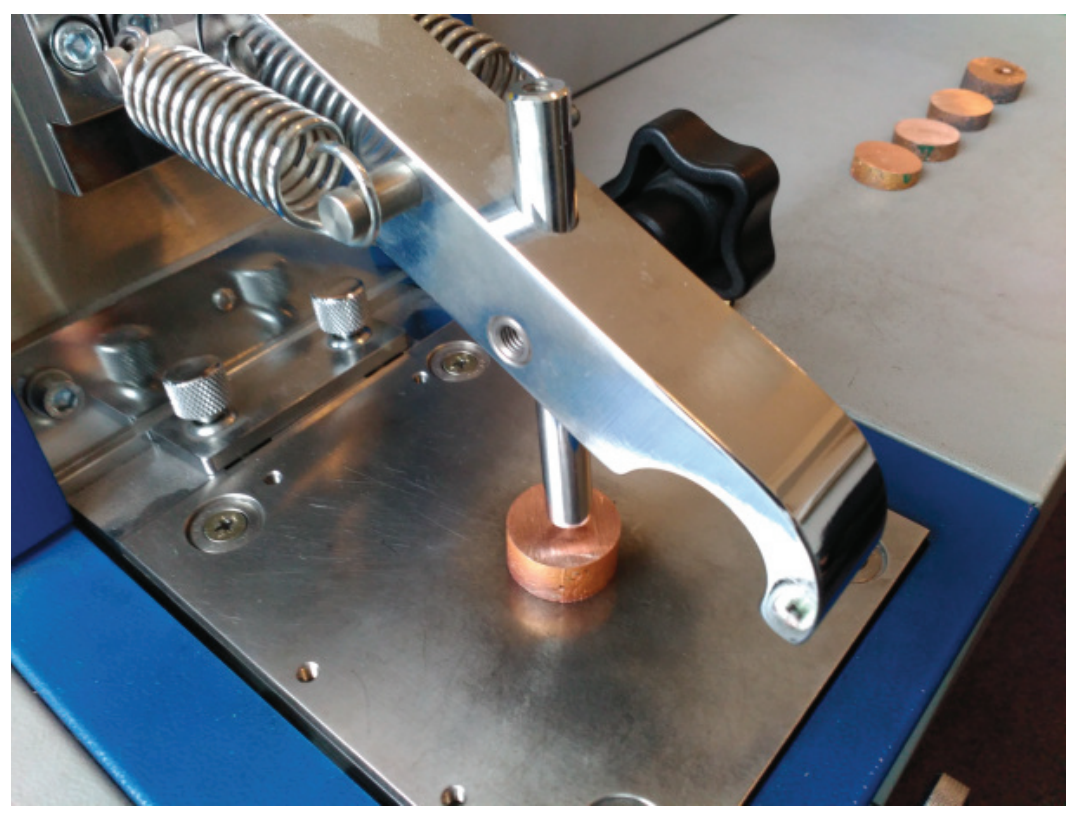

Figure 4 Measurement of Cu castings - OES method

Content of $\mathrm{Sn}$ and $\mathrm{Cd}$ is low, the values are in the order of thousandths of wt\%. The contents of these metals are not listed in the table. Cobalt passed to the Cu collector depending on the LIB mass input fraction. It was found that after smelting the castings contained up to $1.12 \mathrm{wt} \%$ Co for the highest LIB mass. The carbon content was also determined by the OES method.

The LIB mass after re-melting was again analysed by ED-XRF method. The composition of the residual LIB mass after melting exhibits some depletion of $\mathrm{Co}, \mathrm{Ni}, \mathrm{Al}$ and $\mathrm{Mn}$ metals, but a certain amount of these metals still remains in the LIB mass.

\section{CONCLUSIONS}

A LIB mass was used for the experiment, which was annealed at $500{ }^{\circ} \mathrm{C}$ to constant mass. The contents of the selected metals were determined in the initial state and after annealing. The metal content after annealing in the LIB electrode material increased and the cobalt content was approx. $45 \mathrm{wt} \%$. The annealed mass and pure copper were melted by vacuum induction melting in an Ar atmosphere. The melt was centrifugally cast into a graphite mould. The castings thus prepared were machined and cut in several points. The places of cuts were dry ground and they were used to determine the metal content in the castings. The cobalt content was determined also in the mass that remained after melting. It was found that after smelting the casting contained up to $1.12 \mathrm{wt} \%$ of Co for the highest percentage of LIB mass. The cobalt content in the mass after melting was by several percents lower than the input feedstock, but in spite of that, its content was high. The melting process can be further improved.

\section{ACKNOWLEDGEMENTS}

This paper was created at the Faculty of Metallurgy and Materials Engineering within the Project No. L01203 "Regional Materials Science and Technology Centre - Feasibility Programme" funded by the Ministry of Education, Youth and Sports of the Czech Republic, the project SP2019/43 "Specific

Research in the Metallurgical, Materials and Process Engineering" and the project SP2019/128 "Preparation and optimization of properties of alloys and materials for automotive, electro-technical and biomedical applications and possibilities of their recycling". 


\section{REFERENCES}

[1] WORREL, E. and REUTER, M.A. Handbook of Recycling: state-of-the-art for practitioners, analysts, and scientists. Amsterdam: Elsevier. 2014. p. 581.

[2] PISTOIA, G. Lithium-Ion batteries. Advances and applications. Amsterdam, 2014. p. 612.

[3] GEORGI-MASCHLER, T., et. al. Development of a recycling process for Li-ion batteries. Journal of Power Sources. 2012. vol. 207, pp. 173- 182.

[4] RAMACHANDRA RAO, S. Resource recovery and recycling from metallurgical wastes. Amsterdam: Elsevier, 2006, p. 557.

[5] MIKOLAJCZAK, C., et al. Lithium-Ion batteries hazard and use assessment. Springer New York, 2011, p. 115.

[6] ZHENG, X., et. al. A Mini-Review on Metal Recycling from Spent Lithium-lon Batteries. Engineering. 2018. vol. 4, pp. 361-370.

[7] GAINES, Linda. Lithium-ion battery recycling processes: Research towards a sustainable course. Sustainable Materials and Technologies. 2018. vol. 17.

[8] TAKACOVA, Zita, HAVLIK, Tomas, KUKURUGYA, Frantisek B and ORAC, Dusan. Cobalt and lithium recovery from active mass of spent Li-ion batteries: Theoretical and experimental approach. Hydrometallurgy. 2016. vol. 163, pp. 9-17. 